\title{
O risco nas transações internacionais: problemática jurídica e instrumentos (de defesa)
}

Luiz Olavo Baptista, advogado, doutor em direito pela Universidade de Paris, membro da Societé de Legislation Compareé, professorvisitante da Universidade de Michigan, colaborador-correspondente da Unidroit.

"The lover of intelect and knowledge ought to explore causes of intelligent nature first of all, and seccondly, of those things which, beeing moved by others, are compelled to move others. And this is what we too must do" (Platão, Timaeus, trad. inglesa de Benjamin Jowet, ed. Enc. Brit., Chicago, 1971. p.455).

Tal como o filósofo propunha a respeito das causas das condutas humanas, ao se realizar um negócio, no seio de um sistema jurídico ou no plano transacional, é preciso explorar aquelas causas manifestas e as causas das coisas que,"movidas por outras, são compelidas a mover outras". Aí, nestas últimas, é que reside a incerteza de conduta nos contratos.

As causas de "natureza inteligente", a que se referia Platão, são submetidas ao arnês do pacta sunt servanda e das cláusulas do contrato. As outras são como que incontroláveis, e cobertas em alguns sistemas jurídicos pela "força maior" e pelo "fato do príncipe"; noutros, descrevem-nas expressões como acts of public ennemy, acts of god, unabwendbare gewalt, e tantas outras. A pressão de fatos ou vontades alheias à do contratante foi também reconhecida pelos pós-globadores, através da cláusula rebus sic stantibus, que se dizia ínsita em
Luiz Olavo Baptista

cada contrato, e pela teoria da imprevisão mais desenvolvida já em nosso século.

Ao encarar o problema do risco, a grande questão a enfrentar não é a inexecução voluntária ou dolosa dos contratos, mas, sim, o inadimplemento decorrente de causas previsíveis e alheias à vontade dos contratantes, e que ocorrem ao longo tempo. As cláusulas de força maior, o modelo jurídico das cláusulas de hardship, bem como as cláusulas de congelamento do direito, serão o objeto de nossa atenção.

\section{Força Maior}

Noção oriunda do direito romano, a ocorrência da "força maior não é admitida ou tratada universalmente da mesma maneira. Daí porque, ao redigir um contrato internacional, ou até mesmo em direito interno, os advogados sentem a necessidade (maior ou menor, conforme o país de origem) de definir o que entendem por força maior e o regime aplicável à mesma.

Tratando-se de negócios internacionais, o direito é ainda fluido e em criação, tendo grande im- 
portância a prática, o que nos leva a buscar o método empírico, de preferência ao analítico, para o desenvolvimento deste tema. Assim, procuraremos ver como se tem definido força maior, para, em seguida, ver como se disciplina juridicamente esse evento.

\section{O que é força maior}

Cada sistema jurídico dá a sua própria resposta, a essa como a outras questões. Resposta nuançada pelas variações do tempo, bem como do espaço onde se situem as partes contratantes ou os juízes que examinem a questão. Daí surgirem certas definições que, antropocentricamente, chamaríamos de "clássicas", e outras, de "heterodoxas" ou "menos ortodoxas".

Dentre as primeiras, os de pesquisadores de formação ou de influência francesa ou alemã encontrarão cláusulas redigidas como esta: "force majeure are contingencies caused by neither of the parties and which are unforeseable at the time of concluding the contract, uncontrollable and which render the performance of the contractual obligations impossible..." ou então: "on entend par force majeure tous les evenements independents de la volonté des parties, imprévisibles et inévitables, intervenus après I' entrée en vigueur du contraf'et qui empêchent I'execution integrale ou partielle des obligations dérivant de se contract".

Aí encontramos as qualidades que, nos direitos assemelhados ao nosso, são essenciais para caracterizar a força maior: a imprevisibilidade, a inevitabilidade, e a exterioridade em relação à vontade das partes, donde resulte a impossibilidade de ser cumprida a obrigação.

Mas, juristas que não sofreram a influência teórica do "Code Napoleon" definirão a "força maior" omitindo um ou outro desses elementos: "in the contract 'force majeure' shall mean any occurrence outside the control of the parties preventing or delaying their performance of the contract..."

Como se vê, a "impossibilidade" foi omitida aí, tal como nos outros exemplos seguintes: "en cas de survenance d'événements indépendants de la volonté des parties et d'impossibilité d'execution, totale ou partielle, par une des parties engagêes par la presente convention..." $\mathrm{e}$, "...in case of force majeure of for any reason beyond its control making it impossible dor producer to manufature or to deliver..."

Outras omissões ocorrem, sendo rara a falta de menção à inevitalidade, como neste caso: "force majeure regards all circunstances ocurred after the signature of the contract and as a result of any event of exceptional nature, that could not have been an- ticipated by the contracting parties at the signature of the contract...".

Igualmente raro é omitirem as partes, as conseqüências, do evento sobre a execução do contrato.

Podemos supor que algumas dessas omissões decorram de inadvertências. Outras, porém, resultam do propósito deliberado de atenuar os rigores da definição dada à força maior pela jurisprudência ou legislação do país, como é evidente nestes dois casos: "...tout événement, circonstance ou état de fait que le vendeur ne pouvait raisonnablement ni prevoir niemprecher et auquel il lui a été impossible de porter remède de manière à pouvoir respecter les delais contractuels de livraison", e "by force majeure are to be meant extraordinary events independent of the parties' will that cannot be foressen or averted by them even with due diligence, beeing beyond their control... etc.".

A expressão "beyond the control of the parties", usual, é atenuada, por vezes. Usa-se falar em "beyond the reasonable control of the parties", sendo que se fala também em "evenements rendant momentanément humainement impossible l'éxécution", ou referem-se fatos "making it impossible or exorbitant from an industrial or commercial standpoint to perform", assim como se usam fórmulas ainda mais vagas, do gênero do "circunstances which by the exercise of due dilligence and resonable foresight it could not have prevented or overcome".

Há casos em que se prefere deixar ao critério da jurisprudência, ou dos usos e costumes, a definição de força maior. Noutros, associa-se essa fórmula a uma enumeração dos eventos mais previsíveis na sua imprevisibilidade: terremotos, revoluções, guerras, greves, etc. Finalmente, há quem se coloque nas mãos dos árbitros para definir a força maior, ou estabelece que ambas as partes reconheçam a sua ocorrência, como em certa cláusula, onde, após enumerar as circunstâncias clássicas, concluia-se: "...or by other causes which can be recognized by both parties as being cases of force majeure, for being beyond their control."

A maior parte dos redatores de contratos, especialmente os oriundos de países de tradição da common law, não deixa de relacionar as circunstâncias constitutivas de força maior. A providência é válida para prevenir litígios, e poderíamos agrupar esses eventos em determinados tipos:

- cataclisma: terremotos, tufões, tempestades, incêndios, aluviões, inundações, seca, raios, congelamento de estradas e linhas férreas, epidemias, onde os ingleses usam a expressão acts of god e os países socialistas empregam acts of the elements como fórmula genérica que, ou engloba todos esses 
cataclismas, ou inclui os olvidados na enumeração;

- conflitos armados: guerra, revoluções, atos terroristas, bloqueios, tal como, por exemplo, na cláusula seguinte: "war, hostilities (whether war be declared or not) invasion, act of foreign enemics, rebellion, revolution, insurrection of military, or usurped power, civil war, or lotherwise tham among the contractor's own employees) riots, commotion or disorder";

- conflitos do trabalho: tal como se lê em certa cláusula: "grèves générales, grèves organisées syndicalement dans l'entreprise du vendeur et dans le entreprise de ses sous-traitants";

- fato do príncipe: nele incluídas as proibições de exportação e importação, a impossibilidade de obter autorizações ou alvarás de construção de fundos, especialmente moeda estrangeira, restrições ao uso de energia, e outros atos da administração que se procuram englobar em fórmulas amplas: "...acts of government or any government authority or representative rhereof (whether or not legally valid)...";

- dificuldades de transporte ou aprovisionamento, como: "...impossibility ot the use of railway, port, airtport, river transport, roads..." "...manque de wagons ou carriers", "...grave crise de revitaillement ou matiéres indispensables à la production..." entre outras.

- quebras de máquinas e acidentes análogos: constituem o último tipo de evento contemplado nas cláusulas de força maior.

É interessante notar que a enumeração pode ser interpretada de diversas maneiras ou desempenhar diferentes funções. Terá caráter exemplificativo, ilustrativo, ou limitativo. Acrescente-se que na redação dessas cláusulas, além dessa questão de determinar qual a função da lista de eventos, cabe perguntar-se sobre a interpretação a ser dada a cada evento: qualquer inundação? qualquer guerra? que greves? e daí para fora. A dimensão e a extensão dos efeitos do evento de força maior hão sempre de ser avaliados caso a caso. Ocorrerá a impossibilidade de fornecimento quando há greve ferroviária? Não poderia o transporte ser feito por caminhão? Outras questões do gênero podem sempre se colocar. Trata-se, pois, de aspecto a ser discutido e estudado com cuidado, para que a redação seja perfeita, quer se deseje desde logo uma definição precisa, quer deixando para os tribunais competentes decidirem segundo a lei aplicável ao contrato.

Pois bem, ultrapassadas as questões conceituais, ao redigir a cláusula é preciso atentar para os aspectos regulamentares.

\section{A regulamentação da força maior}

Concretizada a previsão, e ocorrendo o evento de força maior, a cláusula deve estatuir o comportamento das partes à partir daí.

Usualmente, estabelece-se o requisito de notificação do evento, a forma da prova de sua ocorrência, a sanção, a exoneração do devedor, a suspensão da execução do contrato ou a extensão de seu termo, a responsabilidade pelas despesas, a obrigação de tentar contornar os efeitos da força maior, seu término e os casos em que caberá rescisão ou renegociação.

Vejamos, pois, esses aspectos da regulamentação da força maior, a partir da constatação de sua ocorrência.

\section{A notificação do evento}

Os efeitos importantes que um evento de força maior tem sobre a execução, em um contrato, impõe a necessidade de se dar notícia dele, rapidamente, à outra parte. "Rapidamente" é conceito utilizado nas redações de diferentes cláusulas, em suas várias versões: as soon as possible, aussitôt within a reasonable time. Mas é preciso também dizer à partir de quando decorre esse prazo quando este for fixo, quinze, vinte, trinta ou mais dias: se é do evento, ou do conhecimento do mesmo pelo devedor, hipótese mais favorável a este.

Prevê-se, em geral, a notificação por carta registrada, telex ou telefonema. Há cláusulas que apenas exigem que a notificação seja expressa, se determinar a forma como se fará: "la partie que invoque un cas de force majeure devra aussitôt adresser une notification expresse á I' autre partie".

Noutro extremo, certa cláusula, de que temos conhecimento, impunha duas comunicações escritas: "the concerned party has to notify the other party of setting in of the events mentioned in $\$ 17.0 \mathrm{im}$ mediatly by cable and confirm it by a registered letter".

Exige-se quase sempre que a notificação vá acompanhada da prova do fato de força maior. A forma dessa prova deve ser, na medida do possível, estabelecida na cláusula regulamentar. O uso corrente é a menção a certidões de "autoridades e competentes" ou declarações de câmaras de comércio (hipótese comum nos negócios com países socialistas).

\section{Cláusulas exoneratórias}

A demora ou imperfeição na notificação podem ser sancionadas, e isso ocorre em alguns contratos, através de "cláusulas de atribuição de responsabilidade", por exemplo: "la partie qui n'a pas res- 
pecté cette condition sera reputée avoir pris à charge irrevocablement les risques et toutes consequences de la force majeure respective".

Sendo a contrapartida dessas cláusulas, a de exoneração do devedor, que pode ser total quando ele tiver cumprido a sua obrigação de notificar: "the contractor shall not be responsible for any harm or damages that are due to force majeure".

Há casos em que se amputam, ou elidem, as obrigações do contratante pelo período de duração de força maior: "... the party so prevented or delayed shall be excused fron such performance to the extent and during the period of prevention or delay, without, however, extending the terms of this agreement".

Hipótese em que não ocorreria a rescisão do contrato. Pode, também, ser contemplada a suspensão dos prazos do contrato, resguardada sua execução, em seguida, por exemplo: "as obrigações afetadas pela força maior são prorrogadas automaticamente por um prazo igual ao atraso decorrente do fato de força maior", ou, mais genericamente, "...the delivery periods shall be increased as far as necessary, to compensate the reduction in deliveries caused by the force majeure."

Não seria útil enumerar todas as nuances da exoneração ou diminuição da responsabilidade do devedor nesses casos, porque elas resultam, sempre, de negociações. Importante e tão só marcar as soluções mais típicas.

\section{Obrigações resultantes do evento}

Ocorrendo o fato de força maior, impõe-se, geralmente, às partes ou a uma delas, envidar esforços para contornar o acontecido. Esse ônus não existe sempre, pois, como vimos, há hipóteses em que a ocorrência do fato de força maior faz cessar todos os efeitos do contrato.

Quando há previsão de suspensão ou alteração de prazos ou outras condições do contrato o que vai acontecer em economias planejadas ou no fornecimento de bens que incluem tecnologias exclusivas - é usual encontrarmos a cláusula que obriga o devedor a tentar evitar ou contornar os efeitos da força maior. Esse esforço é de difícil prova ou constatação, assim como de duvidosa avaliação por se tratar de conceito subjetivo.

Não nos parece haver dúvida de que, do ponto de vista teórico, no nosso sistema de direito e nos que lhe são aparentados, o evento de força maior é definido como 'irresistível', o que tornaria qualquer esforço para contorná-lo inútil ou, se contornável fosse, não seria o caso de força maior. A concessão de prazos e a suspensão do contrato por certo período dão exemplos de quem entenda que, por passageira a força maior, seus efeitos não são absolutos.

Outros esforços podem ser reclamados do devedor, ainda que de modo genérico: "...parties shall exercise all due dilligence to minimise the extent of the prevention or delay in the performance of the contract generally" ou ainda: "en cas de force majeure, les parties contractantes sont tenues de conduire tous le efforts necessaires dans le bût de suprimmer et/ou diminuer les difficultés et les dommanges provoqués, auquel cas l'autre partie sera constanment tenue au courant de la situation dans le cas contraire, la parter defaillante poura se voir réclamer des dommanges et interêts par l'autre partie."

Da idéia da possibilidade de contornar a força maior resulta uma outra conseqüência: mantido o contrato com a sua suspensão ou alterações decorrentes da força maior - é preciso restaurar o estado primitivo das coisas, quando isso é possível, após o término dos efeitos da força maior. Por isso é usual a cláusula ou parágrafo que prescreve a obrigação da parte afetada pela força maior, de comunicar o fim dos efeitos desta.

\section{Rescisão ou renegociação}

Os efeitos da força maior, podem ser de tal monta que impeçam definitivamente, ou torne inútil, a execução do contrato. Daí ser prevista a rescisão ou renegociação do contrato.

À rescisão aludimos atrás. Outra possibilidade é a renegociação, para o que um roteiro é predeterminado no próprio contrato, em geral remetendose as partes a árbitros que, por eqüidade, proponham as novas condições do contrato.

Os contratos por nós pesquisados no arquivo de nosso escritório de advocacia, e no da Feduci, e aos quais vimos nos referindo, assinam um prazo, após o qual, não-cessados nem contornados os efeitos do evento de força maior, chega-se à rescisão ou renegociação; e, quando cabível a renegociação, também se prevê, em alguns casos, que passado certo tempo, sem novo acordo, o contrato se rescindirá.

A medida da tolerância e dos prazos é dada pela necessidade do fornecimento e resulta de tratativas e negociações prévias. Trata-se de ponto crucial para a renegociação e redação do contrato, quer pelos seus efeitos, quer pelo que indica ao fornecedor o grau de necessidade do adquirente da prestação contratada.

Nos contratos financeiros em geral a estipulação mais corriqueira é de remeter as partes à arbitragem e prever o término do contrato, sendo, ainda assim, raras as cláusulas de força maior, em ra- 
zão da regra genera non pereunt. Com efeito, o pagamento em dinheiro quase nunca é impedido pelos fatos de força maior. Entretanto, a intervenção estatal pode afetar transferências de fundos e constituir, dessarte, causa de força maior que impeça o cumprimento da obrigação de pagar.

Em um contrato do mercado de eurodivisas, pode-se ver uma dessas raras cláusulas: "if, by reason of the non-availability to the bank of eurodollars in the London Interbank Eurocurrency Market, it becomes impossible for the bank to make or continue, to make the commitment available on the basis contemplated by this agreement, the bank shall promptly so notify the borrower, whereupon the bank and the borrower shall search for an alternative basis for continuing the commitment whether by making the commitment available from some source other than the London Interbank Eurocurrency Market or from other branch or branches of the bank. If such alternative is not available or is not acceptable to the borrower, the bank shall make available in the New York market, to an American subsidiary of borrower, under the guarantee of the borrower, dollars at the same rate at which the bank would make an advance to a major United States domestic company in similar amounts and maturities."

Assim olhados os aspectos mais importantes da força maior, examinemos, a seguir, a noção de hardship.

\section{As cláusulas de hardship}

A força maior, como vimos, é, na tradição da família romanístico-germânica de direitos, o advento de um fato imprevisível, inevitável, exterior à vontade do devedor, que torne impossível a execução da obrigação.

Constatamos, também, que em certos contratos se procura contornar esse evento, com suas conseqüências, de formas diversas, na medida em que as diferentes legislações o permitem. Das restrições doutrinárias, jurisprudenciais ou legislativas à força maior, nasceu outro conceito, filho da autonomia da vontade.

O hardship assemelha-se à força maior no tocante à imprevisibilidade e à inevitabilidade do evento, mas dela se distancia porque o evento gerador do hardship apenas torna mais generosa a execução do contrato.

A noção de hardship, dominante nos contratos internacionais, tem como contraparte a de imprevisão, ou, mais precisamente, a formulação da imprevision dos direitos belga e francês.

Como nem todas as legislações admitem a teoria da imprevisão - ou a cláusula rebus sic stan- tibus - é na autonomia da vontade que as cláusulas de hardship se apóiam. Por isso, é a extensão dessa autonomia que admitirá, ou não, a sua validade.

O hardship afasta-se da teoria da lesão porque esta refere-se ao desequilíbrio de prestações desde o início do contrato, ou mesmo antes deste, e aquele cuida do desequilíbrio ocorrido durante a execução, por força de fato imprevisível e inevitável.

As cláusulas de hardship estão ligadas como concepção econômica às de correção monetária ou indexação, podendo-se até relacioná-la às cláusulasouro! Assim é, porque todos esses tipos de cláusulas prevêem a modificação das condições do contrato quando se alteram certas circunstâncias externas a ele, dando ao contrato um dinamismo e adaptabilidade que Ihe permita sobreviver às parcelas econômicas.

Entretanto, as mencionadas cláusulas de correção monetária ou indexação, relacionadas à cláusula-ouro também conhecidas como cláusulas de "conservação ou manutenção do valor", representam, "une methode permettant de répartir les risques monetaries entre les parties à une transaction internacionale" (S.A. Sillard, Clauses de mantien de valeur dans les transactions internacionales, Clunet, $1972,214)$ e apresentam uma automaticidade e complexidade, que as tornam tão indesejáveis quanto mais o são do ponto de vista de diversas legislações, que as proibem por julgá-las inflacionárias.

Já as cláusulas de hardship pertencem à espécie das cláusulas ditas "de readaptação", espécie a que pertencem as government take clause, a first refusal clause, a "cláusula do cliente mais favorecido" e a de força maior, atrás examinada.

As cláusulas de hardship, embora pudessem ser encontradas desde o início do século, embrionárias e redigidas de forma suscinta e sintética, nos últimos seis ou sete anos tornaram-se mais freqüentes, como que refletindo as incertezas de nossos dias. As cláusulas atuais são complexas e detalhadas, como as de força maior.

É nos contratos a longo termo que as encontramos: fornecimento de matérias-primas; obras de execução prolongada, como por exemplo vias férreas e oleodutos; construção de usinas siderúrgicas e petroquímicas; e finalmente, nos contratos ligados a tecnologias ditas "de ponta", como a eletrônica e os sistemas informáticos, bem como nos empréstimos internacionais.

Do ponto de vista de sua redação, podemos decompor as cláusulas de hardship em dois aspectos, que correspondem à mecânica adotada para o estudo da força maior: a definição da hipótese, e sua regulamentação. 


\section{O que é hardship}

Um autor definiu a cláusula de hardship como "celle aux termes de laquelle les parties pourront demander un réménagement du contrat qui les lie si un changement intervenu dans les données initiales au regard desquelles elles s'étaient engagées vient à modifier l'equilibre de ce contrat au point de faire subir à l'une d'elles une rigueur (hardship) injuste" (Bruno Oppetit, L'adaption des contrats internationaux au changements de circonstance, Clunet 1975, 794).

Mas a definição é teórica, e na verdade, não é a doutrina quem a dá, mas as partes na redação do contrato. Assim é que precisamos recorrer à redação deste para ver como o conceito é, ainda, fluido.

Das cláusulas de hardship, de nosso conhecimento, todas equacionam a hipótese de incidência, prevendo os eventos e suas conseqüências.

A primeira afirmativa nelas é a de que as circunstâncias tenham sofrido uma mudança, donde decorrerá um desequilíbrio de prestações, inexistentes inicialmente. Por exemplo: "sipár suite de consequence d'ordre economique ou commercial survenant après la signature du contrat et dehors des previsions normales des parties, l'économie des rapports contractuele verrait à être modifié au point de rendre prejudiciable pour l'une des parties l'exécution de ses obrigations".

Fala-se nessas cláusulas de "circunstances en dehors des previsions normales des parties", de "survenance d'événements économiques imprevisibles ou exclus par les previsions qu'ont admises acheteur et vendeur", ou de "...an interving event or change of circunstances beyond said party's control when acting as a resonable and prudent operator."

As circunstâncias, imprevisíveis sempre, e exteriores à vontade das partes, ao contrário do que ocorre com a força maior, não se devem às forças da natureza ou a fatos de terceiros, mas a movimentos do ambiente do contrato, especialmente os da economia.

Entretanto esses fatos, imprevisíveis e inevitáveis, e suas consequeências, são diversos e podem ser definidos genericamente: "if for any bona fide cause the revenue accruing to you for this transaction is insufficiente to meet the costs." ou exemplificativamente: "toutes difficultês relatives à l'obtention de devises, à des mesures de politique commerciale, au contingentement, à la manipulation monetaire".

Como se vê, o "fato do príncipe" poderia se incluir entre os eventos causadores do hardship, mas estes são, quase sempre, de natureza econômico- monetária, não sendo porém excluídos os fatos políticos, como em certa cláusula: "dans le cas on un événement grave, de caractere économique, financier ou politique."

Há exemplos também, de alterações de ordem jurídica, mas aí a cláusula se assemelhará às de "congelamento de direito", de que adiante trataremos: tal como ocorre com a força maior, há quem procure exemplificar quais são os eventos. Às vezes a exemplificação expõe uma certa previsibilidade do fato, como em contrato onde se dizia que o advento de uma "environmental prescription forcing the designated receiving smelter to undertake new endeavours for providing, eliminating and reducing certain elements in its production process or its emissions...".

Não são esquecidas nessas enumerações novas incidências fiscais, políticas discriminatórias contra certos produtos ou a sua procedência, alterações na taxa de câmbio, moratórias, pedidos de consolidação de dívidas, atrasos em conversão da moeda, ou até mesmo mudanças de políticas de um banco (o BIRD, numa cláusula que examinamos).

Há ainda cláusulas mistas em que ocorre uma enumeração e uma disposição geral: "if owing to changed circunstances such as changes in monetary values or discriminatory governamental action or regulations or differential customs duties...".

Finalmente, há quem use a fórmula genérica associada à exclusão de certos eventos já contemplados no contrato ou na cláusula: "price control by the goverment of the state of the relevant buyer affecting the price of... in the market shall not be considered to constitute substancial hardship".

Pois bem, ocorrido o evento, a conseqüência que legitima a invocação do hardship é o prejuízo de uma das partes. Mas, o que é prejuízo? Um ganho menor que o previsto? Uma receita igual ou menor que a despesa? Prejuízo no balanço daquele exercício ou nos vários em que o contrato esteja sendo cumprido?

Para evitar dúvidas, qualifica-se o prejuízo: falase em "un prejudice matériel exagéré" ou "substantial and disproportionate prejudice to either party", ou ainda "substantial economic hardship", havendo ainda caso de expressões de difícil avaliação, como "undue hardship to either party", ou "unfairness, or substantial and disproportionate prejudice to the interests of either party."

Os melhores exemplos são os que definem ou permitem definir a ocorrência do hardship, a partir de circunstâncias específicas: "si les conditions du marché devenient telles que le prix de vente se rélévait inferieur à..." 


\section{A regulamentação da hardship}

Ocorrida a hipótese, ela é regulamentada, havendo procedimentos que se assemelham aos adotados para o caso da força maior, o que terá influenciado os redatores das primeiras cláusulas de hardship.

Em certa cláusula prevê-se que: "the prejudiced party may, by notice, request the other for a meeting to determine if said occurrence has happened... If the seller and the buyer have not agreed, within sixty days, either party may require the matter to be submitted for arbitration. The arbitration shall determine whetter the aforesaid occurrence has happened."

A redação da cláusula deixa entrever a possibilidade do beneficiário da hardship tentar escapar e cuida, desde logo, do compromisso de arbitragem, pelo menos no tocante ao aspecto inicial da questão: saber se ocorreu ou não a hardship.

Estipula-se também um prazo de carência a partir do qual a cláusula é aplicável, assim como o prazo para que as negociações se realizem.

O objetivo da hardship é a revisão da avença ou, a isso não se chegando, a rescisão do contrato.

Há quem não disponha sobre a forma como se dará a revisão do contrato, e há os que estabelecem os critérios que se aplicarão: tais critérios podem ser subjetivos, como a menção à "loyauté reciproque", à "fairness of the parties", ou a condições "appropriatte and equitable under the circunstances"; podem também ser critérios objetivos, visando recolocar as partes em posição de equilíbrio comparável à que existia no momento da celebração do contrato. Usa-se, também, misturar os dois critérios, ou ainda referir-se à eqüidade, no caso de arbitragem.

No tocante à rescisão, é admissível imaginar que ocorra independentemente de previsão contratual, pela via judicial ou da arbitragem; pode ainda, ser prevista expressamente, o que parece mais prudente e correto. A rescisão decorrerá, aí, seja do consenso das partes de que não é possível ou conveniente negociar, seja da iniciativa da parte prejudicada, havendo cláusulas que cogitam de qualquer dessas hipóteses. Pode ainda a rescisão emanar da ação ou decisão de terceiros, como os árbitros, por previsão contratual, expressa, ou deixando as partes que o Judiciário resolva a questão.

Para concluir, podemos lembrar que é possível encontrar cláusulas que convencionam a suspensão do contrato para a renegociação e o retorno à normalidade anterior à hardship; assim como cláusulas unilaterais do tipo: "la banque pourra mettre fin à toutes les utilisations du crédit dans le cas de survenance d'événements, notanment d'événements politique exterieurs ou interieurs susceptibles de perturberle fonctionement de l'entreprise didebiteur ou des institutions politiques ou financières de son pays".

Um último fator exterior à vontade das partes pode afetar a vida dos contratos: é o tempo.

Vejamos como se tenta fugir aos seus efeitos.

\section{O tempo e o contrato internacional}

O problema dos conflits mobiles é clássico. Não esgota, entretanto, a problemática do tempo em relação ao contrato internacional. A primeira interferência do tempo acontece na celebração do contrato entre ausentes: qual o momento da efetivação? Mas não é desse aspecto que falaremos agora.

É que tendo desempenhado o seu papel na formação do contrato, o tempo afeta-o durante a vigência.

Para contemplar essa influência criaram-se as chamadas "cláusulas de estabilização".

Já se escreveu que o direito aplicável, "because it sustains, may also dissolve the contractual bond", o que, em outras palavras significa que o direito escolhido, pelas partes, quando da celebração, para reger o contrato, por via direta ou indireta, pode ser outro no momento do exame do mesmo contrato pelo juiz.

Por outro lado, o princípio do direito brasileiro, segundo o qual a lei nova deve respeitar o ato jurídico perfeito, não é universal, quer quanto ao seu reconhecimento ou à extensão em que é aplicado. Sem entrar em detalhes dessa questão, conhecida e examinada exaustivamente, resta-nos encarar as consequeências das mudanças na legislação nos contratos internacionais.

$\mathrm{Na}$ common law, diz-se que "law applies as it exists from time to time and not merely as it stoods at the time of the contract".

Em países como a França, que aplicam no seu direito interno a regra da proteção do ato jurídico perfeito, da mesma forma como no Brasil, isso ocorre em relação aos contratos internacionais. Nestes, há como que um encapsulamento temporal do contrato no direito da época da celebração, que se mantém até mesmo quanto aos efeitos posteriores: de fato, cláusulas monetárias, até mesmo a "cláusula-ouro", são aplicadas ainda que leis francesas ou estrangeiras. promulgadas mais tarde, Ihes neguem validade.

Num caso, État Francais V. Comité de la Bourse d'Amsterdam ICass. ler. janvier 1950, Rev. Cr. Dr. Int. Pr. 1950, 609; Sirey 1951, 1.1; Dalloz 1951, 749; Clunet $1950,1.196)$, isso ficou claro, assim como a ins- 
piração política da common law, a do tipo brasileiro, e a de conteúdo político, como a francesa, entretanto, perdem a sua influência em nossos dias.

A instabilidade da economia, hoje, leva as partes, seja nos contrastes de efeitos internacionais, seja nos demais, a procurar prevenir-se contra mudanças não só da legislação como da economia. O interesse não é sempre o de dar rigidez absoluta às condições do contrato, mas torná-lo flexível para que possa ser executado num clima de eqüidade. Nesse sentido, a orientação da common law quanto ao direito aplicável é mais correta que a excessiva rigidez quanto à aplicação do direito em vigor na época da contratação a toda a relação contratual. Com efeito, não é razoável que o contrato seja imune aos efeitos da alteração legislativa, mas sofra os das mudanças econômicas. A reação do contrato ao ambiente deve ser coerente: flexível ou 'congelado' em qualquer dos casos.

Embora a tendência seja em direção à flexibilidade há um campo em que se procura, ainda, recorrer às cláusulas de estabilização. É nos contratos em que um Estado é parte. Diversos países seguiram a regra usual da common law e aplicam a lei nova indicada pela regra de conflito de leis quando esta é a do próprio ou de outro país.

Em diversos casos de conflito, os árbitros, quase sempre de países do Hemisfério Norte, decidiram que, quando um país muda a sua legislação de maneira que afete substancialmente o contrato, essa mudança pode acarretar a responsabilidade internacional desse Estado. Esqueceram-se que as leis não afetam exclusivamente esse contrato, mas, sim, todos os contratos... A atitude é mais política que jurídica, voltada contra as mudanças econômicas e políticas ocorridas em países em desenvolvimento ou Estados nascidos de colônias.

Interessante notar que quando a questão foi à Corte Permanente Internacional de Justiça e à Corte Internacional da Justiça, esta não chegou a uma decisão definitiva.

A solução correta repousa na boa fé que deve informar todos os atos dos contratantes. As mudanças feitas em boa fé, inspiradas no interesse públi$c o$, e que se impuseram em uma situação na qual afetarão todos os contratos, devem aplicar-se inclusive aos celebrados com estrangeiros, a quem não pode nem deve o Estado conceder tratamento especial.

A lógica desse pensamento é confirmada pelo fato de que, quando desejam privilegiar determi- nado contrato, certos países incluem cláusulas de estabilização nos seus contratos.

As cláusulas de estabilização são encontradas com mais freqüência nos chamados "economic development agreements", e em certos contratos para prospecção de petróleo.

Como exemplos dos primeiros podemos citar o acordo Fiat-Minas Gerais ou o contrato celebrado entre o governo de Gana e a Valco (Volta Aluminium Company Ltd) que prevê: "except as otherwise expressaly provided werein, this agreement and the scheduled documents shall be construed and have effect in accordance with the law of Ghane as it exists at the 22nd day of January, 1962"...().

Essa cláusula prevê a incorporação ao contrato, como se fossem cláusulas suas, dos dispositivos, então em vigor, do direito de Gana.

Outras asseguram que não se aplicará a legislação subseqüente no que agravar a situação do contratante estrangeiro. Há, ainda, as que apenas visam às incidências fiscais (é o caso do acordo Fiat-Minas Gerais). Outras cláusulas, ainda, extravasam a estabilização propriamente dita, objetivando a inclusão de vantagens atribuídas legislativamente a terceiros: são as "most favored company clauses", e sua contraparte e "most favored-nation clause". Nesta última é o contratante estrangeiro que deve conceder ao Estado contratante as vantagens que deu a outros Estados em contratos do mesmo gênero.

As limitações desta exposição e do interesse desse tipo de cláusulas fazem com que nos detenhamos por aqui, a aridez do assunto é aparente, porque bem dizia o poeta:

"Tudo isto não é só humano e limpo, mas também belo. E tem ao fim um destino marítimo, um vapor onde embarquem as mercadorias de que as cartas e faturas tratam.

Complexidade da vida! As faturas são feitas por gente.

Que tem amores, ódios, paixões políticas, às vezes crimes.

E são tão bem escritas, tão alinhadas, tão independentes de tudo isso...

Venham dizer-me que não há poesia no comércio, nos escritórios!

Ora, ela entra por todos os poros..." 